\title{
Antidepressants and Anti-Inflammatory Drugs Differentially Reduce the Release of NGF and BDNF from Rat Platelets
}

Authors

Affiliation

\section{T. Hochstrasser, D. Ehrlich, B. Sperner-Unterweger, C. Humpel}

Department of Psychiatry and Psychotherapy, Laboratory of Psychiatry and Exp. Alzheimer's Research, Innsbruck Medical University, Innsbruck, Austria

\author{
Key words \\ - platelets \\ - neurotrophic factor \\ - antidepressants \\ - serotonin
}

\section{Abstract \\ $\nabla$}

Introduction: Platelets store serotonin and brain-derived neurotrophic factor (BDNF) as well as amyloid precursor protein and nerve growth factor (NGF), thus platelets are of special interest in depression and Alzheimer's disease, respectively. Both diseases are associated with inflammation and release of NGF or BDNF from platelets may play a potent role.

Methods: Platelets were isolated from adult Sprague-Dawley rats and were incubated with anti-inflammatory drugs (ibuprofen and indomethacin) and antidepressants (citalopram, paroxetine and sertraline) (final concentration: $0.3 \mu \mathrm{M}$ ) with or without $2 \mathrm{mM}$ calcium chloride. The release of NGF and BDNF was analyzed in comparison to

\section{Introduction}

$\checkmark$

accepted $\quad 08.05 .2012$

\section{Bibliography}

DOI http://dx.doi.org/ 10.1055/s-0032-1314843

Published online ahead of print:

14 June 2012

Pharmacopsychiatry 2013;

46: 29-34

(c) Georg Thieme Verlag KG Stuttgart · New York

ISSN 0176-3679

\section{Correspondence}

\section{Humpel}

Department of Psychiatry and Psychotherapy

Laboratory of Psychiatry and Exp. Alzheimer's Research Innsbruck Medical University Anichstraße 35

A-6020 Innsbruck

Austria

Tel.: +43/512/504 23712

Fax: +43/512/504 23713

christian.humpel@i-med.ac.at
Blood platelets reveal remarkable parallels to the brain. Platelets are the main source of serotonin and a dysfunction of the serotonergic system is implicated in depression [1]. Platelets also express amyloid precursor protein (APP) and contain beta-amyloid $(A \beta)$, which aggregates to amyloid plaques in Alzheimer's disease (AD). Furthermore, platelets contain growth factors such as nerve growth factor (NGF) and brain-derived neurotrophic factor (BDNF) and since both diseases are associated with inflammation, the activation of platelets and the release of NGF or BDNF may play a potent role.

The neurotransmitter serotonin is produced by neurons of the dorsal raphe nucleus and is involved in the regulation of, e. g., mood and cognition [2]. In the blood, platelets are the main source of serotonin and platelets express different serotonin receptors and the serotonin transporter (SERT) $[3,4]$. SERT on platelets influences the plasma serotonin levels and the number of SERTs per platelet is sensitive to selective serot- serotonin release from rat platelets after 10 or $60 \mathrm{~min}$.

Results: Spontaneous release of serotonin and BDNF was approximately $10-15 \%$ of total serotonin or BDNF content in platelets, but nearly all NGF was released within $10 \mathrm{~min}$. All antidepressants increased the serotonin release from rat platelets. NGF release was reduced by sertraline, paroxetine and ibuprofen, but only when calcium was present, except for sertraline after $10 \mathrm{~min}$. BDNF release was only reduced by ibuprofen when calcium was added.

Conclusion: We conclude that antidepressants and anti-inflammatory drugs differentially influence the NGF and BDNF release, in a time-, doseand calcium-specific pattern.

onin reuptake inhibitors (SSRIs), which are the most commonly used antidepressants [5]. Serotonin is released from activated platelets and serotonin from platelets may play a role in neuroinflammation [6].

Growth factors are expressed in most tissues and stimulate cellular growth, proliferation and cellular differentiation. NGF and BDNF belong to the neurotrophin family and promote neurogenesis, synaptic plasticity and cell survival in the brain [7]. In the blood NGF and BDNF are stored in platelets and can bind to platelet receptors [810]. NGF is implicated in inflammatory and neurodegenerative disorders [11]. It has been reported that NGF can bind to specific platelet receptors and can induce platelet aggregation [8]. So far, it has been shown that peripheral levels of NGF are not increased by antidepressant treatment [12]. However, not much is known on the release of NGF from platelets. BDNF has been implicated in inflammatory and stress-related disorders such as depression, where low BDNF levels have been reported [11,13]. Antidepressants increase BDNF levels in blood by inducing 
BDNF release from platelets $[14,15]$. Also in stressed rodents the administration of BDNF has been shown to evoke an antidepressant-like effect [16]. The secretion of platelet content requires complex processes, including the formation of prostaglandins that can be abolished by anti-inflammatory drugs with cyclooxygenase (COX)-inhibitory properties [17].

So far, the impact of antidepressants and anti-inflammatory drugs on NGF and BDNF release from platelets is unknown and partly not consistent in the literature. Therefore, the present study aims to investigate the effects of anti-inflammatory drugs (ibuprofen and indomethacin) and antidepressants (citalopram, paroxetine and sertraline) on NGF and BDNF release from rat platelets. We will investigate the effects of calcium on the release in a time-dependent manner.

\section{Materials and Methods}

$\nabla$

Blood collection and platelet isolation and treatment

Platelets were isolated as reported previously [18]. In total 24 adult Sprague-Dawley rats were used. They were anaesthetized with a high dose of thiopental (Sandoz, Kundl, Austria) and blood was drawn directly from the heart by using a butterfly blood collection system (Becton Dickinson, Schwechat, Austria). The blood was collected in EDTA tubes (Sarstedt, Wr. Neudorf, Austria) and centrifuged at $250 \mathrm{~g}$ for $15 \mathrm{~min}$ to obtain plateletrich plasma (PRP). $500 \mathrm{nM}$ prostaglandin-I2 sodium salt ( $\mathrm{PGI}_{2}$, prostacyclin-sodium salt, Sigma, Vienna, Austria) was added to prevent platelet activation during processing. Platelets were separated from PRP by centrifugation at $2300 \mathrm{~g}$ for $10 \mathrm{~min}$ and washed in calcium-free Tyrode buffer $(136 \mathrm{mM} \mathrm{NaCl}, 2.7 \mathrm{mM}$ $\mathrm{KCl}, 12 \mathrm{mM} \mathrm{NaHCO} 3,0.42 \mathrm{mM} \mathrm{NaH}_{2} \mathrm{PO}_{4}, 1 \mathrm{mM} \mathrm{MgSO}_{4}, 5 \mathrm{mM}$ glucose, $\mathrm{pH}$ 6.5). Washed platelets were centrifuged at $2300 \mathrm{~g}$ for $10 \mathrm{~min}$ and were finally resuspended in $1 \mathrm{~mL}$ Tyrode buffer (adjusted to $\mathrm{pH}$ 7.4). All centrifugation steps were performed at room temperature. Freshly isolated platelets $\left(1 \times 10^{8}\right)$ were incubated with $0.3 \mu \mathrm{M}$ citalopram (Sigma) or $0.3 \mu \mathrm{M}$ ibuprofen (Sigma) or $0.3 \mu \mathrm{M}$ indomethacin (Sigma) or $0.3 \mu \mathrm{M}$ paroxetine (Smith Kline, Vienna, Austria) or $0.3 \mu \mathrm{M}$ sertraline (Pfizer, Vienna, Austria) (final concentration) at $37^{\circ} \mathrm{C}$ for $10 \mathrm{~min}$ or $60 \mathrm{~min}$ in Tyrode buffer ( $\mathrm{pH} 7.4$ ). In addition, platelets were incubated with or without $2 \mathrm{mM}$ calcium chloride $\left(\mathrm{Ca}^{2+}\right)$. To stop the release $1.7 \mathrm{mM}$ EDTA (final concentration) were added and samples were centrifuged at $2300 \mathrm{~g}$ for $10 \mathrm{~min}$. The supernatant was collected and frozen at $-80^{\circ} \mathrm{C}$ until analysis.

\section{Serotonin analysis by HPLC}

Serotonin was measured by high-performance liquid chromatography (HPLC) and electrochemical detection as reported previously [19]. Samples were thawed and $20 \mu \mathrm{L}$ supernatant were injected into the HPLC. The samples were separated on a reversed-phase C18 Nucleosil column (Bartelt, Graz, Austria) at a flow rate of $1 \mathrm{~mL} / \mathrm{min}$ using the following mobile phase: $0.05 \mathrm{M}$ trichloric acid (Merck, Darmstadt, Germany), 0.26mM EDTA (Merck), $1.36 \mathrm{mM} \mathrm{NaCl}$ (Roth, Karlsruhe, Germany), $1.81 \mathrm{mM}$ heptanesulfonic acid (Sigma) and 15\% acetonitrile (BDH Prolabo, Vienna, Austria) in HPLC water. Detection was performed with an electrochemical detector (Antec II, Leyden, Netherlands) at $+0.55 \mathrm{~V}$ and $30^{\circ} \mathrm{C}$. All unknown samples were correlated to external standards of serotonin (Sigma). Analysis was performed by measuring peak heights at the respective retention times of the substances (serotonin $7.8 \mathrm{~min}$ ).

\section{NGF and BDNF immunoassays}

BDNF and NGF levels were measured using commercial enzymelinked immuno-sorbent assay (ELISA) kits (Promega, Mannheim, Germany). Detection of BDNF and NGF was performed as described by the manufacturer. Briefly, $100 \mu \mathrm{L}$ standards or samples were added to coated wells and incubated for $6 \mathrm{~h}$ at room temperature. After washing, the detection antibodies were added and samples were incubated over night at $4^{\circ} \mathrm{C}$. Wells were washed again and incubated with horseradish peroxidase conjugate for $2.5 \mathrm{~h}$. After washing, TMB one solution was added. After $10 \mathrm{~min}$ the reaction was stopped and the absorbance was measured at $450 \mathrm{~nm}$ in a Zenyth 3100 ELISA reader.

\section{Data and statistical analysis}

All data obtained from NGF, BDNF and serotonin release were analyzed with a one-way ANOVA and a subsequent Fisher LSD posthoc test, where $p<0.05$ was considered statistically significant. Quantitative data are presented as mean values \pm SEM in \% of totals. Due to variabilities in isolation and analysis, the number $(\mathrm{n})$ of treatments was not always identical.

\section{Results \\ $\nabla$}

\section{Control conditions}

The total content of $1 \times 10^{8}$ platelets was $747 \pm 215 \mathrm{ng}$ serotonin $(\mathrm{n}=17), 255 \pm 49 \mathrm{pg}$ NGF $(\mathrm{n}=9)$ and $418 \pm 100 \mathrm{pg}$ BDNF $(\mathrm{n}=15)$ ( $\bullet$ Table 1). Under calcium-free conditions only a low amount of serotonin and BDNF (approximately 10-16\%) of total content was released after 10 and $60 \mathrm{~min}$, however, almost all NGF was released ( $\bullet$ Table 1 ). Calcium did not significantly influence the release of serotonin, although there was a tendency for an increase ( $\bullet$ Table 1 ). Calcium significantly reduced the NGF release after $60 \mathrm{~min}$, but not after $10 \mathrm{~min}$ ( Table 1 ). Calcium significantly increased the release of BDNF after both 10 and $60 \min$ (๑ Table 1 ).

Effects of drugs on serotonin release from rat platelets All 3 antidepressants (citalopram, sertraline or paroxetine) increased the serotonin release under calcium-free conditions after 10 and $60 \mathrm{~min}$ ( $\bullet$ Table $\mathbf{2 A}$ ). The anti-inflammatory drug indomethacin increased the serotonin release under calciumfree conditions only after $60 \mathrm{~min}$. Ibuprofen did not alter the serotonin release under calcium-free conditions ( 0 Table 2A). Under calcium conditions ibuprofen and paroxetine significantly released more serotonin after $10 \mathrm{~min}$, while all other treatments with calcium did not increase the serotonin release from platelets either after 10 or $60 \mathrm{~min}$ ( $\bullet$ Table 2B).

\section{Effects of drugs on NGF release from rat platelets}

Under calcium-free conditions only sertraline reduced the NGF release from platelets after $10 \mathrm{~min}$ ( $\bullet$ Table 3A). NGF release was reduced under calcium conditions by ibuprofen, paroxetine and sertraline after $10 \mathrm{~min}$, but not after $60 \mathrm{~min}$ ( $\odot$ Table 3B). Citalopram and indomethacin did not affect NGF release ( $\bullet$ Table 3A, B).

\section{Effects of drugs on BDNF release from rat platelets}

No effect on BDNF release was seen under calcium-free conditions with all tested drugs ( $\bullet$ Table 4). Treatment of rat platelets with citalopram, paroxetin, sertraline and indomethacin did not influence the release of BDNF under calcium conditions after 10 and $60 \mathrm{~min}$ ( $\odot$ Table 4 A, B). BDNF release was significantly 
Table 1 Spontaneous release of serotonin, NGF and BDNF from platelets and effects of calcium.

\begin{tabular}{|c|c|c|c|c|c|c|c|c|c|}
\hline & Serotonin & $\mathbf{p}_{1}$ & $\mathbf{p}_{2}$ & NGF & $\mathbf{p}_{1}$ & $\mathbf{p}_{2}$ & BDNF & $\mathbf{p}_{1}$ & $\mathbf{p}_{2}$ \\
\hline \multirow[t]{2}{*}{ total } & $747.2 \pm 215(17)$ & & & $254.7 \pm 48.9(9)$ & & & $417.7 \pm 99.9(15)$ & & \\
\hline & {$[100 \pm 28.7(17)]$} & & & {$[100 \pm 19.2(9)]$} & & & {$[100 \pm 23.9(15)]$} & & \\
\hline \multirow[t]{2}{*}{ control/10 min } & $75.5 \pm 0.3(14)$ & - & - & $230.2 \pm 52.7(9)$ & - & - & $55.1 \pm 12.9(12)$ & - & - \\
\hline & {$[10.1 \pm 2.4(14)]$} & & & {$[90.4 \pm 20.7(9)]$} & & & {$[13.2 \pm 3.1(12)]$} & & \\
\hline \multirow[t]{2}{*}{ control $+\mathrm{Ca}^{2+} / 10 \mathrm{~min}$} & $192.0 \pm 0.01$ (9) & ns & - & $248.6 \pm 32.6(9)$ & ns & - & $301.6 \pm 45.1(9)$ & $* * *$ & - \\
\hline & {$[25.7 \pm 8.4(9)]$} & & & {$[97.6 \pm 12.8(9)]$} & & & {$[72.2 \pm 10.8(9)]$} & & \\
\hline \multirow[t]{2}{*}{ control/60 min } & $38.1 \pm 9.0(12)$ & - & ns & $227.4 \pm 32.1(9)$ & - & ns & $66.4 \pm 12.5(12)$ & - & ns \\
\hline & {$[5.1 \pm 1.2(12)]$} & & & {$[89.3 \pm 12.6(9)]$} & & & {$[15.9 \pm 3.0(12)]$} & & \\
\hline \multirow[t]{2}{*}{ control $+\mathrm{Ca}^{2+} / 60 \mathrm{~min}$} & $120.3 \pm 36.6(7)$ & ns & ns & $122.5 \pm 19.4(10)$ & $* *$ & $* *$ & $397.6 \pm 51.0(9)$ & $* * *$ & ns \\
\hline & {$[16.1 \pm 4.9(7)]$} & & & {$[48.1 \pm 7.6(10)]$} & & & {$[95.2 \pm 12.2(9)]$} & & \\
\hline
\end{tabular}

Rat platelets were isolated from whole blood. Platelets were incubated with or without $2 \mathrm{mM} \mathrm{Ca}^{2+}$ at $37^{\circ} \mathrm{C}$ for 10 or $60 \mathrm{~min}$. Totals and supernatants were collected and serotonin, NGF and BDNF release was analyzed by HPLC-EC and ELISA, respectively. Values are given as mean $\pm \mathrm{SEM} \mathrm{ng} / \mathrm{ml} / 10^{8}$ platelets (serotonin) or $\mathrm{pg} / \mathrm{ml} / 10^{8} \mathrm{platelets}$ (NGF, BDNF). Values in brackets give the mean \pm SEM \% of total control. The number of analyzed samples is given in parenthesis. Statistical analysis was performed by one-way ANOVA with a Fisher LSD posthoc test. $\mathrm{p}_{1}=$ control vs. control $+\mathrm{Ca}^{2+} ; \mathrm{p}_{2}=10 \mathrm{~min}$ vs. $60 \mathrm{~min} ;{ }^{*} \mathrm{p}<0.05 ;{ }^{* *} \mathrm{p}<0.01 ;{ }^{* * *} \mathrm{p}<0.001 ; n s$, not significant

Table 2 Serotonin release by anti-inflammatory drugs and antidepressants.

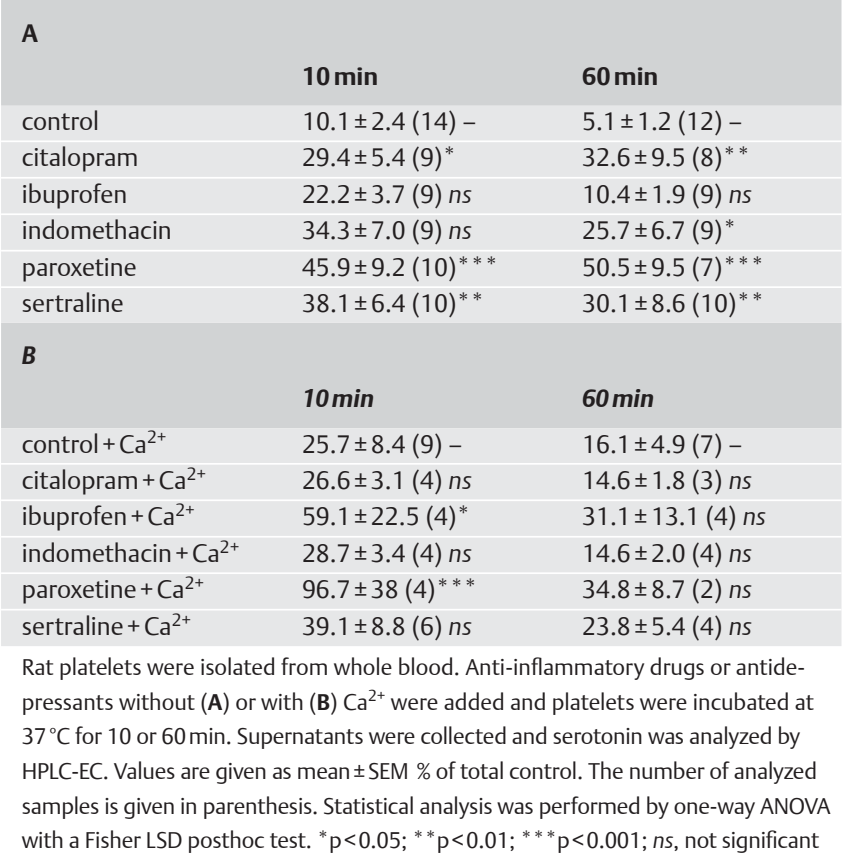

reduced by the anti-inflammatory drug ibuprofen after 10 and $60 \min (\bullet$ Table 4B).

\section{Discussion}

$\nabla$

Our present study shows that anti-inflammatory drugs and antidepressants influence release of NGF and BDNF from rat platelets in a calcium-sensitive way. Serotonin was used as a positive control.

\section{Platelets and storage of molecules}

Platelets have 3 types of secretory granules: dense bodies, alpha granules and lysosomes. Dense bodies contain ATP, ADP, serotonin and calcium. Alpha granules contain different growth factors, such as platelet-derived growth factor (PDGF), transforming growth factor-beta 1 (TGF-1 $\beta$ ), platelet factor 4 as well as other proteins necessary for functional activity (e.g., fibrinogen, von Willebrand factor, factors V and VIII). Lysosomes contain acid hydrolases [17]. The granules content is secreted following acti- vation by a wide variety of stimuli, such as ADP and thrombin. Thrombin is a very strong stimulus that has been widely used to study platelet secretion. Thrombin causes exocytosis of dense bodies and degranulation of alpha granules, while thrombin induces alpha granule secretion at a lower concentration than the secretion of dense bodies. Furthermore, it was shown that the secretion induced by different stimuli requires the formation of arachidonic acid metabolites or depends on temperature or calcium concentration [17]. Also, it has been shown that NGF is stored in dense bodies, while BDNF is stored in alpha granules $[17,20]$.

\section{Role of calcium on platelet release}

Calcium regulates various cellular processes, including cellular activation and degranulation in platelets [21]. Elevation in calcium concentrations derive from either the release of intragranular stores or extracellular calcium, which plays an important role in platelet activation and secretion. The calcium ionophore A23187 causes platelet secretion in a similar manner as thrombin and high concentrations of calcium and thrombin lead to an immediate release of diverse growth factors including PDGF and TGF-1 $\beta[22,23]$. In human and rat platelets a weak inhibiting effect of calcium on serotonin reuptake has been shown [24]. In our study we used $2 \mathrm{mM}$ calcium, which is a well established extracellular concentration. We show that calcium had slight but not significant effects on serotonin release and a pronounced strong effect on BDNF release from platelets after 10 and $60 \mathrm{~min}$.

\section{Serotonin release from platelets as a positive control}

Already in the 1960s Bartholini and Pletscher [25] had shown that platelets incubated in physiological medium (e.g., Tyrode buffer) release only a small amount of serotonin, which is induced by thrombin within a few minutes. The vesicular monoamine transporter inhibitor reserpine induces the release of serotonin from platelets and inhibits the reuptake of serotonin in dense granules [26]. Several antidepressants directly increase the release of serotonin and inhibit the reuptake of serotonin into dense granules $[27,28]$. In addition, SSRIs induce depletion of platelet serotonin levels and reduce platelet activation $[29,30]$. Our data are in full agreement, showing low secretion of serotonin and that SSRIs inhibit the reuptake of serotonin from platelets.

NSAIDs are COX inhibitors, which suppress prostaglandin synthesis from arachidonic acid and suppress platelet aggregation 
Table 3 NGF release by anti-inflammatory agents and antidepressants.

\begin{tabular}{|c|c|c|}
\hline \multicolumn{3}{|l|}{ A } \\
\hline & $10 \mathrm{~min}$ & $60 \mathrm{~min}$ \\
\hline control & $90.4 \pm 20.7(9)-$ & $89.3 \pm 12.6(9)-$ \\
\hline citalopram & $91.6 \pm 8.3(4) n s$ & $85.6 \pm 5.1(6) n s$ \\
\hline ibuprofen & $86.8 \pm 8.9(4) n s$ & $73.6 \pm 8.4(5) \mathrm{ns}$ \\
\hline indomethacin & $112.0 \pm 5.5(6) n s$ & $69.6 \pm 15.2(6) n s$ \\
\hline paroxetine & $87.0 \pm 15.1$ (6) ns & $84.1 \pm 18.9(5) n s$ \\
\hline sertraline & $41.0 \pm 15.1(5)^{* *}$ & $60.3 \pm 15.9(5) n s$ \\
\hline \multicolumn{3}{|l|}{ B } \\
\hline & $10 \mathrm{~min}$ & $60 \mathrm{~min}$ \\
\hline control $+\mathrm{Ca}^{2+}$ & $97.6 \pm 12.8(9)-$ & $48.1 \pm 7.6(10)-$ \\
\hline citalopram $+\mathrm{Ca}^{2+}$ & $63.8 \pm 7.4(6) n s$ & $56.0 \pm 10.7$ (5) ns \\
\hline ibuprofen + $\mathrm{Ca}^{2+}$ & $53.3 \pm 5.0(5)^{*}$ & $59.2 \pm 10.9(5) n s$ \\
\hline indomethacin $+\mathrm{Ca}^{2+}$ & $63.3 \pm 6.2(6) \mathrm{ns}$ & $60.8 \pm 5.5(6) n s$ \\
\hline paroxetine $+\mathrm{Ca}^{2+}$ & $55.7 \pm 8.2(6)^{*}$ & $70.1 \pm 7.1$ (4) ns \\
\hline sertraline $+\mathrm{Ca}^{2+}$ & $56.8 \pm 13.6(5)^{*}$ & $30.8 \pm 8.5(5) n s$ \\
\hline \multicolumn{3}{|c|}{$\begin{array}{l}\text { Platelets were isolated and incubated with or without anti-inflammatory drugs or } \\
\text { antidepressants without (A) or with (B) } \mathrm{Ca}^{2+} \text {. Platelets were incubated at } 37^{\circ} \mathrm{C} \text { for } \\
10 \text { or } 60 \text { min. Supernatants were collected and NGF was analyzed by ELISA. Values } \\
\text { are given as mean } \pm \text { SEM \% of total. The number of analyzed samples is given in } \\
\text { parenthesis. Statistical analysis was performed by one-way ANOVA with a Fisher LSD } \\
\text { posthoc test. }{ }^{*} \mathrm{p}<0.05 ;{ }^{* *} \mathrm{p}<0.01 ; n \mathrm{n} \text {, not significant }\end{array}$} \\
\hline
\end{tabular}

Table 4 BDNF release by anti-inflammatory agents and antidepressants.

A

\begin{tabular}{|c|c|c|}
\hline & $10 \mathrm{~min}$ & $60 \mathrm{~min}$ \\
\hline control & $13.2 \pm 3.1(12)-$ & $15.9 \pm 3.0(12)-$ \\
\hline citalopram & $10.9 \pm 4.0(8) n s$ & $18.4 \pm 1.9(6) n s$ \\
\hline ibuprofen & $16.0 \pm 5.4(6) n s$ & $18.7 \pm 6.3(7) n s$ \\
\hline indomethacin & $18.9 \pm 3.9(8) n s$ & $21.6 \pm 6.0(8) n s$ \\
\hline paroxetine & $17.1 \pm 4.3(9) n s$ & $20.2 \pm 2.9(7) n s$ \\
\hline sertraline & $13.4 \pm 2.8(8) n s$ & $25.4 \pm 5.8(7) n s$ \\
\hline \multicolumn{3}{|l|}{ B } \\
\hline & $10 \mathrm{~min}$ & $60 \mathrm{~min}$ \\
\hline control $+\mathrm{Ca}^{2+}$ & $72.2 \pm 10.8(9)-$ & $95.2 \pm 12.2(9)-$ \\
\hline citalopram +Ca ${ }^{2+}$ & $67.3 \pm 7.7(6) n s$ & $95.3 \pm 14.5(5) \mathrm{ns}$ \\
\hline ibuprofen $+\mathrm{Ca}^{2+}$ & $43.8 \pm 16.3(5)^{*}$ & $57.2 \pm 21.3(5)^{* *}$ \\
\hline indomethacin $+\mathrm{Ca}^{2+}$ & $76.6 \pm 13.7(6) n s$ & $88.5 \pm 17.6(6) n s$ \\
\hline paroxetine $+\mathrm{Ca}^{2+}$ & $58.9 \pm 20.2(6) n s$ & $92.0 \pm 24.8(4) n s$ \\
\hline sertraline $+\mathrm{Ca}^{2+}$ & $77.8 \pm 16.4(6) n s$ & $85.7 \pm 17.9(4) n s$ \\
\hline \multicolumn{3}{|c|}{$\begin{array}{l}\text { Platelets were isolated from rat blood. Anti-inflammatory drugs or antidepressants } \\
\text { without }(\mathbf{A}) \text { or with }(\mathbf{B}) \mathrm{Ca}^{2+} \text { were added and platelets were incubated at } 37^{\circ} \mathrm{C} \text { for } 10 \\
\text { or } 60 \mathrm{~min} \text {. Supernatants were collected and BDNF was analyzed by ELISA. Values are } \\
\text { given as mean } \pm \text { SEM \% of total. The number of analyzed slices is given in parenthe- } \\
\text { sis. Statistical analysis was performed by one-way ANOVA with a Fisher LSD post-hoc } \\
\text { test. }{ }^{*} \mathrm{p}<0.05 ;{ }^{* *} \mathrm{p}<0.01 ; n \text {, not significant }\end{array}$} \\
\hline
\end{tabular}

[31]. COX inhibitors do not inhibit serotonin reuptake, but they restrain the stimulation by cytokines. Inhibition of pro-inflammatory cytokines leads to a down-regulation of indoleamine 2,3-dioxygenase (IDO). IDO is the rate-limiting enzyme in the tryptophan-kynurenine pathway and triggers the synthesis of serotonin to kynurenine [32]. Thereby COX inhibitors may directly influence the serotonin metabolism and serotonin availability. In the present study we show that NSAIDs did not increase serotonin release after $10 \mathrm{~min}$, but indomethacin enhanced the release after $60 \mathrm{~min}$. It seems likely that the effects of NSAIDs are time-, dose- and drug-specific. Previously it had already been shown that NSAIDs inhibit the secretion only at very low agonist concentrations [17].
NGF release from platelets and effects of drugs The function of NGF in blood is unclear and little is known about NGF in platelets. A recent study has shown that NGF serum concentrations were not altered by antidepressant treatment and that serum concentrations were not related to the antidepressant type [12]. Our data show, for the first time, that NGF is markedly released from rat platelets. This was an interesting novel observation showing that almost all (90\%) of NGF is spontaneously released from platelets. In the brain, release of NGF is highly regulated and influenced by neuronal activity [33]. NGF is generated from a precursor molecule (proNGF), which undergoes processing to generate mature NGF [33]. The NGF precursor and proteases are stored in neuronal compartments from which they are simultaneously released after neuronal stimulation [34]. In neurons, a basal constitutive secretion of NGF can be partially blocked by, e.g., lowering the incubation temperature [33]. In platelets, NGF is contained in dense bodies and mainly the whole granular content is spontaneous released within minutes. However, serotonin release accounts only for about $10-15 \%$ and thus it seems likely that NGF and serotonin release are differentially regulated, because markedly more NGF is released than serotonin. This finding points to uptake mechanisms, degradation or binding to extracellular molecules or to platelet membranes. Our data show for the first time that sertraline spontaneously reduced release of NGF, but only after $10 \mathrm{~min}$ under calcium-free or calcium-containing conditions. It is fully unclear why the release was not altered after $60 \mathrm{~min}$. This may indeed indicate that the effect of sertraline is only a fast and transient one and that NGF is further released with time. Similarly, ibuprofen and paroxetine also reduced NGF release but only when calcium was present. Thus, we conclude that the release of NGF from platelets is uncontrolled and can only be partly and transiently inhibited by some specific drugs. The mechanism of such a fast release needs to be further explored in detail.

\section{BDNF release from platelets and effects of drugs}

Stress activates several neurotransmitters and the endocrine system including the hypothalamic-pituitary-adrenal (HPA) axis as a key hormonal component [35]. BDNF signaling plays a critical role in the regulation of the HPA axis suggesting an endocrine role for BDNF $[36,37]$. In depression the HPA axis is disturbed and BDNF serum levels are decreased. However, the function of BDNF in the blood is still poorly understood and conflicting results about BDNF serum, plasma and platelet BDNF levels have emerged. In serum of antidepressant-naïve or -free depressed patients decreased BDNF concentrations have been observed. The serum BDNF levels increased after antidepressant treatment $[14,38,39]$. It has been suggested that BDNF released from platelets directly correlate to serum BDNF levels. Indeed, platelet BDNF is reduced in depressed patients and serum BDNF levels are enhanced after stimulation on platelets by antidepressant treatment [10,15]. Furthermore, Serra-Millas et al. [40] reported high platelet BDNF and low plasma BDNF levels in healthy controls. Recently it has been reported that antidepressants induce a marked BDNF release from rat platelets in a time- and dosedependent manner [15]. Contrary, it has been shown that collagen induces platelet activation and aggregation is inhibited by antidepressants by inhibiting granule secretion from platelets [28]. Another study showed that aspirin (a non-specific COXinhibitor) reduces the release of BDNF from platelets [41], while a recent study reported that aspirin did not affect BDNF release 
[42]. Taken together, there is a strong controversy on showing release of BDNF from platelets. It seems likely that the type of isolation of platelets may markedly affect the results, such as, e.g., using EDTA/citrate tubes, puffers with or without calcium, $\mathrm{pH}$ during isolation and use of diverse inhibitors. Our data are in clear contrast to those of Watanabe et al. [15] showing that all antidepressants did not affect the release of BDNF under calcium-free conditions. Unfortunately, Watanabe et al. [15] did not provide detailed information on platelet isolation, thus differences in platelet preparation may account for the differences to our study. Furthermore, they did not provide raw values, making it difficult to directly compare our data. Our data also show that only ibuprofen affected BDNF release but only when calcium was present. This goes in line with the work of Fujimura et al. [43], who observed a rapid release of BDNF from human platelets with the calcium ionophore A23187. We suggest that ibuprofen reduced BDNF release possibly involving COX inhibition and calcium-mediated release from alpha granules.

\section{Conclusion}

\section{$\checkmark$}

In our present study we use platelets from rats, which allows us to study cellular mechanisms in a simple homogenous and reproducible cell type. Our study is the first to investigate the influence of 3 antidepressants (citalopram, sertraline, paroxetine) and 2 non-steroidal anti-inflammatory drugs (ibuprofen, indomethacin) with or without calcium on NGF and BDNF release and serotonin as a control from rat platelets. The influence of antidepressants and anti-inflammatory drugs on NGF and BDNF release differs depending on the drug type, dose and maybe on the incubation period. It is concluded that the release of the 2 growth factors NGF and BDNF contributes to blood levels, which may indicate a role in platelet-derived function, including vascular mechanisms. Further studies should clarify the mechanisms of NGF and BDNF release also in human platelets.

\section{Acknowledgements}

This study has been supported by the Austrian Science Funds L429-B05. This study was supported by the European Community (Moodinflame, Early diagnosis, treatment and prevention of mood disorders targeting the activated inflammatory response system. FP7-Health-2007 Project no: 222963).

\section{Conflict of Interest}

$\nabla$

The authors declare no conflicts of interest.

\section{References}

1 Owens MJ. Selectivity of antidepressants: from the monoamine hypothesis of depression to the SSRI revolution and beyond. J Clin Psychiatry 2004; 4: 5-10

2 Strüder HK, Weicker H. Physiology and pathophysiology of the serotonergic system and its implications on mental and physical performance. Int J Sports Med 2001; 22: 467-481

3 Lesch KP, Wolozin BL, Murphy DL et al. Primary structure of the human platelet serotonin uptake site: identity with the brain serotonin transporter. J Neurochem 1993; 60: 2319-2322

4 Hoyer D, Hannon JP, Martin GR. Molecular, pharmacological and functional diversity of 5-HT receptors. Pharmacol Biochem Behav 2002; 71: $533-554$
5 Brenner B, Harney JT, Ahmed BA et al. Plasma serotonin levels and the platelet serotonin transporter. J Neurochem 2007; 102: 206-215

6 Horstman LL, Jy W, Ahn YS et al. Role of platelets in neuroinflammation: a wide-angle perspective. J Neuroinflammation 2010; 3: 7-10

7 Castrén E, Võikar V, Rantamäki T. Role of neurotrophic factors in depression. Curr Opin Pharmacol 2007; 7: 18-21

8 Chekalina ND, Klyushnik TP, Brusov OS et al. Identification of specific binding sites for nerve growth factor on human blood platelets and membranes from bovine brain. Bull Exp Biol Med 1996; 121: 271-273

9 Radka SF, Holst PA, Fritsche $M$ et al. Presence of brain-derived neurotrophic factor in brain and human and rat but not mouse serum detected by a sensitive and specific immunoassay. Brain Res 1996; 709: 122-301

10 Lee BH, Kim YK. Reduced platelet BDNF level in patients with major depression. Prog Neuropsychopharmacol Biol Psychiatry 2009; 33: 849-853

11 Ziegenhorn AA, Schulte-Herbrüggen O, Danker-Hopfe $H$ et al. Serum neurotrophins - a study on the time course and influencing factors in a large old age sample. Neurobiol Aging 2007; 28: 1436-1445

12 Hellweg R, Ziegenhorn A, Heuser I et al. Serum concentrations of nerve growth factor and brain-derived neurotrophic factor in depressed patients before and after antidepressant treatment. Pharmacopsychiatry 2008; 41: 66-71

13 Shelton RC. Cellular mechanisms in the vulnerability to depression and response to antidepressants. Psychiatr Clin North Am 2000; 23: 713-729

14 Aydemir O, Deveci A, Taneli F. The effect of chronic antidepressant treatment on serum brain-derived neurotrophic factor levels in depressed patients: a preliminary study. Prog Neuropsychopharmacol Biol Psychiatry 2005; 29: 261-265

15 Watanabe K, Hashimoto E, Ukai $W$ et al. Effect of antidepressants on brain-derived neurotrophic factor (BDNF) release from platelets in the rats. Prog Neuropsychopharmacol Biol Psychiatry 2010; 34: $1450-1454$

16 Siuciak JA, Lewis DR, Wiegand SJ et al. Antidepressant-like effect of brain-derived neurotrophic factor (BDNF). Pharmacol Biochem Behav 1997; 56: 131-137

17 Zucker MB, Nachmias VT. Platelet activation. Arteriosclerosis 1985; 5: 2-18

18 Ehrlich D, Hochstrasser T, Humpel C. Effects of oxidative stress on amyloid precursor protein processing in rat and human platelets. Platelets 2011, Epub ahead of print

19 Hochstrasser T, Ullrich C, Sperner-Unterweger B et al. Inflammatory stimuli reduce survival of serotonergic neurons and induce neuronal expression of indoleamine 2,3-dioxygenase in rat dorsal raphe nucleus organotypic brain slices. Neuroscience 2011; 184: 128-138

20 Lommatzsch M, Zingler D, Schuhbaeck $K$ et al. The impact of age, weight and gender on BDNF levels in human platelets and plasma. Neurobiol Aging 2005; 26: 115-123

21 Varga-Szabo D, Braun A, Nieswandt B. Calcium signaling in platelets. J Thromb Haemost 2009; 7: 1057-1066

22 Martineau I, Lacoste E, Gagnon G. Effects of calcium and thrombin on growth factor release from platelet concentrates: kinetics and regulation of endothelial cell proliferation. Biomaterials 2004; 25: 4489-4502

23 Roussy Y, Bertrand Duchesne MP, Gagnon G. Activation of human platelet-rich plasmas: effect on growth factors release, cell division and in vivo bone formation. Clin Oral Implants Res 2007; 18: 639-648

24 Jensen PN, Smith DF, Poulsen JH et al. Effect of flunarizine and calcium on serotonin uptake in human and rat blood platelets and rat synaptosomes. Biol Psychiatry 1994; 36: 118-123

25 Bartholini G, Pletscher A. Two types of 5-hydroxytryptamine release from isolated blood platelets. Experientia 1964; 20: 376-378

26 Rudnick G, Humphreys CJ. Platelet serotonin transporter. Methods Enzymol 1992; 215: 213-224

27 Serebruany VL, Glassman AH, Malinin AI et al. Selective serotonin reuptake inhibitors yield additional antiplatelet protection in patients with congestive heart failure treated with antecedent aspirin. Eur J Heart Fail 2003; 5: 517-521

28 Tseng YL, Chiang ML, Huang TF et al. A selective serotonin reuptake inhibitor, citalopram, inhibits collagen-induced platelet aggregation and activation. Thromb Res 2010; 126: 517-523

29 Hergovich N, Aigner M, Eichler HG et al. Paroxetine decreases platelet serotonin storage and platelet function in human beings. Clin Pharmacol Ther 2000; 68: 435-442

30 Blardi $P$, de Lalla A, Urso $R$ et al. Activity of citalopram on adenosine and serotonin circulating levels in depressed patients. J Clin Psychopharmacol 2005; 25: 262-266 
31 Akagi Y, Nio Y, Shimada S et al. Influence of nonsteroidal anti-inflammatory drugs on the antiplatelet effects of aspirin in rats. Biol Pharm Bull 2011; 34: 233-237

32 Dantzer $R, O^{\prime}$ Connor JC, Freund GG et al. From inflammation to sickness and depression: when the immune system subjugates the brain. Nat Rev Neurosci 2008; 9: 46-56

33 Lessmann V, Gottmann K, Malcangio M. Neurotrophin secretion: current facts and future prospects. Prog Neurobiol 2003; 69: 341-374

34 Bruno MA, Cuello AC. Activity-dependent release of precursor nerve growth factor, conversion to mature nerve growth factor, and its degradation by a protease cascade. Proc Natl Acad Sci USA 2006; 103 : 6735-6740

35 Chaouloff F. Physiopharmacological interactions between stress hormones and central serotonergic systems. Brain Res Brain Res Rev 1993; 18: 1-32

36 Smith MA, Makino S, Kim SY et al. Stress increases brain-derived neurotrophic factor messenger ribonucleic acid in the hypothalamus and pituitary. Endocrinology 1995; 136: 3743-3750

37 Lebrun B, Bariohay B, Moyse E et al. Brain-derived neurotrophic factor (BDNF) and food intake regulation: a minireview. Auton Neurosci 2006; 126-127: 30-38
38 Karege F, Perret G, Bondolfi $G$ et al. Decreased serum brain-derived neurotrophic factor levels in major depressed patients. Psychiatry Res 2002; 109: 143-148

39 Shimizu E, Hashimoto K, Okamura $N$ et al. Alterations of serum levels of brain-derived neurotrophic factor (BDNF) in depressed patients with or without antidepressants. Biol Psychiatry 2003; 54: 70-75

40 Serra-Millàs M, López-Vílchez I, Navarro $V$ et al. Changes in plasma and platelet BDNF levels induced by S-citalopram in major depression. Psychopharmacology (Berl) 2011; 216: 1-8

41 Storey RF. Biology and pharmacology of the platelet P2Y12 receptor. Curr Pharm Des 2006; 12: 1255-1259

42 Stoll P, Plessow A, Bratke $K$ et al. Differential effect of clopidogrel and aspirin on the release of BDNF from platelets. J Neuroimmunol 2011; 238: 104-106

43 Fujimura $H$, Altar CA, Chen $R$ et al. Brain-derived neurotrophic factor is stored in human platelets and released by agonist stimulation. Thromb Haemost 2002; 87: 728-734 